\title{
GUERRA Y DIPLOMACIA ROMANA CON LOS PUEBLOS VENCIDOS DE GRECIA Y ORIENTE: NOTAS SOBRE LA DEDITIO Y LA OPPUGNATIO EN LAS GUERRAS CIVILES DE APIANO
}

\author{
WAR AND ROMAN DIPLOMACY WITH THE DEFEATED PEOPLES OF \\ GREECE AND THE EAST: NOTES ON DEDITIO AND OPPUGNATIO IN \\ APPIAN'S CIVIL WARS
}

\section{Pablo Castro Hernández}

Universidad Andrés Bello Facultad de Educación y Ciencias Sociales Avenida República 276, Santiago, Chile pabcastroh@gmail.com

\begin{abstract}
Resumen
En este texto analizamos las prácticas bélicas y los derechos de guerra de la República Romana con los pueblos vencidos de Grecia y Oriente a partir de la obra Guerras civiles de Apiano (siglo II d. C.). Primero, revisamos las nociones de la guerra y la diplomacia romana, considerando enfoques historiográficos y culturales. Posteriormente, estudiamos los conceptos de deditio y oppugnatio, como recursos de guerra que consolidan la imagen de poder de Roma, a partir de los cuales Roma obtiene
\end{abstract}


suministros económicos y militares, que favorecen el control de sus dominios y la conquista de nuevos territorios.

Palabras clave: guerra, diplomacia, guerras civiles, república romana, Apiano.

\begin{abstract}
In this study we analyze the Roman Republic's practices and rights of war with regard to the defeated peoples of Greece and the East in the work Civil Wars by Appian (second century $\mathrm{AD})$. First, we review the notions of war and Roman diplomacy, considering historiographic and cultural approaches. Secondly, we study the concepts of deditio and oppugnatio, as resources of war that consolidate the image of power of Rome. Through these concepts, Rome obtains economic and military supplies, which favor the control of its domains and the conquest new territories.
\end{abstract}

Keywords: War, Diplomacy, Civil Wars, Roman Republic, Appian.

Recibido: 08/11/2019

Aceptado: 11/01/2021

Las guerras civiles constituyen un momento de crisis y ruptura en el mundo republicano romano, en el que los conflictos de poder apuntan a una etapa de transformación en Roma y sus provincias aliadas. Esta erosión política, tanto en el primer o segundo triunvirato, y la lucha contra las facciones republicanas, muestra un contexto de división política y social, que no solo repercute en Roma, sino también afecta a sus diversas provincias y estados sometidos a su poder ${ }^{1}$. Sin ir más lejos, y en el contexto del segundo triunvirato ( 43 a 48 a. C.), tanto los triunviros y republicanos expanden sus intereses a Grecia y Oriente con la finalidad de encontrar mayores recursos

Hay un proceso de discordias políticas y sucesivas guerras entre Mario y Sila (80 a. C.), César y Pompeyo (40 a. C.), Octavio y Antonio (44 a. C.-31 d. C.), que reflejan las diversas crisis en el mundo romano. Tal como explican Breed, Damon y Rossi, las guerras civiles comienzan a ser vistas como una forma de locura, furor y enceguecimiento de los ciudadanos romanos que amenaza con aniquilar la República (4-8). 
económicos y suministros de guerra para la lucha que se está librando, por lo que se extienden a algunas embajadas que recuerdan los antiguos tratados y muestran su apoyo a las causas de cada facción. Esto nos lleva a diversas problemáticas en las relaciones diplomáticas y las operaciones de guerra que se establecieron con los acuerdos y desacuerdos políticos entre los romanos y los pueblos aliados ${ }^{2}$.

El presente texto analiza las prácticas bélicas y los derechos de guerra del mundo romano con los pueblos vencidos de Grecia y Oriente durante las guerras civiles (siglo I a. C.). Se examina la diplomacia romana y la aplicación de la deditio y la oppugnatio como recursos de guerra que consolidan la imagen de poder de Roma. Asimismo, ambos conceptos se estudian como fuentes de suministros económicos y militares; sus ganancias y beneficios son utilizados para mantener las empresas bélicas de republicanos y triunviros.

Para esta investigación, hemos considerado la obra Guerras civiles de Apiano, escrita en griego a mediados del siglo II d. C., centrándonos en los discursos de embajadas y las prácticas bélicas del segundo triunvirato de la guerra civil en Roma (43-48 a. C.), particularmente en los libros $\mathrm{IV}$ y $\mathrm{V}^{3}$.

El problema de estudio se centra en los usos y prácticas de la guerra y la diplomacia romana narrada por Apiano, para exponer los castigos y retribuciones para los pueblos vencidos y las justificaciones que impulsan las guerras provocadas por Roma. Hay que destacar que, en los relatos de

2 Cabe mencionar que existe un fuerte impacto en el Mediterráneo dada la crisis que vivía Roma, lo que golpeó de manera directa a los pueblos aliados de la república, que enfrentan demandas de apoyo militar, con la amenaza de la aniquilación definitiva de las ciudades si no cooperan, como también confiscaciones de bienes y solicitudes de tributos y suministros económicos (Millar 227).

3 Apiano fue un historiador originario de Alejandría (Egipto). En un primer momento ocupó cargos administrativos en su ciudad natal y posteriormente actuó como abogado en la corte de los emperadores. El historiador no se dedica a escribir historia de su tiempo, sino que narra la historia de Roma desde sus orígenes hasta el 35 a. C. En el caso de las guerras civiles, destaca la personalidad de sus líderes y, sobre todo, resalta el interés por la serie de revoluciones que propician al desarrollo de la monarquía (Sancho Royo, 7-22; y Bucher 411-58). 
embajadas, Apiano menciona diversos casos de pueblos griegos y orientales vencidos por Roma, cuyas relaciones diplomáticas están sometidas a su poder. Podemos notar cómo los gobernadores y embajadores romanos -republicanos o triunviros- articulan un sentido de supremacía frente al otro derrotado, imponiéndole ciertas condiciones de guerra. En el caso de la deditio, los pueblos sometidos poseen una determinada libertad, pero se encuentran sojuzgados a la soberanía de Roma, debiendo aportar recursos de guerra, ejércitos y tributos para obtener protección y seguridad de los romanos. En la oppugnatio, apreciamos pueblos sometidos de manera violenta, que han faltado a los tratados y pactos, o han sido hostiles con Roma, que-sometidos por la fuerza- deben pagar tributos y diversos recursos o bien son destruidos para rescatar el botín de guerra.

Ahora bien, ¿qué relaciones mantiene Roma con los pueblos vencidos de Grecia y Oriente? ¿En qué medida la deditio y la oppugnatio contribuyen al sostenimiento de la práctica bélica e imperialista de Roma? ¿Y qué representa Asia para los intereses políticos y económicos del mundo romano en el contexto de las guerras civiles?

Consideramos que la práctica bélica y los derechos de guerra aplicados por Roma, ya sea de la facción republicana o de los triunviros, conservan la tradición de la deditio y la oppugnatio como recursos de guerra que permiten fortalecer su imagen y obtener ganancias y beneficios para las empresas bélicas. Si bien existen intereses políticos particulares, ya sea con los triunviros -Antonio y Octavio- o los republicanos -Casio y Bruto-, donde cada uno busca realzar un objetivo político distinto, el modo en el que operan sus prácticas bélicas está basado en la guerra justa, con la que articulan sus discursos diplomáticos sobre acciones hostiles o faltas graves cometidas por las ciudades extranjeras o enemigas, cuestión que permite a los romanos justificar la guerra y castigar y tomar represalia contra dichos estados. Con estas prácticas bélicas, los romanos buscaban beneficios materiales que aportaran suministros de guerra -dinero, soldados u otros recursos-, para financiar y mantener el combate de ambas facciones. Las provincias de Grecia y Oriente constituyen espacios de suministros y riquezas con los que Roma financió sus guerras. 
En otras palabras, el mundo romano articuló las prácticas bélicas y los derechos de guerra en torno a su tradición militar de autodefensa e imperialismo, para realzar su poder por los pueblos vencidos y, sobre todo, para mantener territorios sometidos que pudieran aportar recursos materiales y económicos a los proyectos particulares de cada facción de la guerra civil.

\section{GuERra y diplomaCia romana: algunas PRECISIONES CONCEPTUALES}

El estudio de la guerra y la diplomacia en el mundo romano nos plantea algunas problemáticas conceptuales respecto de actitudes y prácticas en torno a la expansión, el imperialismo y la autodefensa como mecanismos que buscan potenciar el poder de Roma. En los siglos III a I a. C., apreciamos diversas embajadas y guerras contra Cartago, Iliria y el Ponto, entre otros pueblos, en las que Roma buscó establecer su dominio, consolidándose con los triunfos diplomáticos y militares que traían beneficios políticos y económicos para la repúblicát.

De los estudios historiográficos acerca de la diplomacia, Nicolet señala que, dentro de los fundamentos del derecho internacional y la diplomacia romana, algunos historiadores - tales como Mommsen, Lévy-Bruhl y Veyne- proyectan "en el extranjero un enemigo absoluto con el cual no había relaciones posibles", de modo que este terminaba siendo asimilado de forma completa o convertido en vasallo por Roma (748). Otros trabajos de la línea de Catalano, De Martino y Phillipson, indican que en un primer momento "hostis no designaba al enemigo sino al extranjero con el que se suponía que las relaciones eran amistosas" (749). De esta manera, el ius fetiale refleja un

Cabe señalar que el envío y recepción de embajadas muestra el interés de Roma de abrirse y dialogar con otros pueblos, generando diversos tipos de intercambios o resolviendo situaciones fronterizas con los estados vecinos. El hábito diplomático se funde en un sistema de circulación y comunicación que permite la expansión de Roma en el mundo mediterráneo (Eilers 13). 
dispositivo jurídico entre Roma y los pueblos extranjeros, que constituye la base de las relaciones internacionales y la diplomacia, que permitió establecer acuerdos y modos de relación con otras sociedades.

Según Buono-Core, mediante el foedus, Roma integró a los enemigos y grupos vencidos, concediéndoles beneficios y derechos cívicos, con lo cual podía aumentar su potencia y fuerza militar. Mediante estos pactos, Roma estableció una paz permanente para mantener un dominio sobre sus territorios (“Los tratados" 24). Para Veyne, "el pueblo romano era un pueblo rey", las relaciones "con sus súbditos o extranjeros eran un patrocinium", es decir, no existía igualdad entre las partes, sino que eran relaciones "personales, desiguales e informales" (414-5). Roma se diferenció de los otros pueblos, que se encuentran fuera del carácter civilizado, que formaron parte de su sistema como subordinados al poder romano 5 .

La diplomacia romana constituía un mecanismo de dominio, estableciendo negociaciones, acuerdos y paz, que permitía controlar las relaciones políticas. De este modo, las relaciones internacionales de Roma reflejan un recurso de propaganda con el que buscaban "aparecer librando guerras para defenderse y defender a sus aliados" (Buono-Core, Roma republicana 209). Tal como recalca el autor, es un modo publicitario que muestra "la benevolencia y fides de Roma", procurando "ofrecer un pretexto para ir a la guerra" y teniendo el "cuidado de no aparecer como agresores, sino como defensores y yendo a la guerra por obligación” (209) .

La embajada romana se vincula fuertemente con la guerra, en cuanto es el instrumento que puede negociar la paz o anunciar el conflicto. Esta misma embajada puede expresar un recurso con el que Roma justifica las guerras contra sus enemigos ${ }^{7}$. La guerra es una herramienta para expandir

5 Cabe mencionar que hay una clara distinción entre el mundo civilizado y el mundo barbárico, en la que los romanos consideran que "el único medio para lograr igualdad de tratamientos y oportunidades era adquiriendo la civitas romana” (Bancalari 9).

6 No obstante, es importante recalcar que la actitud de los embajadores romanos debía estar centrada en la auctoritas, "con el propósito de mantener el respeto por el poderío romano”. En el desempeño de ese servicio, uno de los objetivos diplomáticos era mostrar "la autoridad, el poder y la majestad de Roma" (Torregaray 322).

Hay que tener presente que el mundo romano, basado en la civitas, forja una base 
el poder, obtener ganancias y recursos, y consolidar su hegemonía frente a los pueblos vencidos ${ }^{8}$. Harris sostiene que el romano realiza la guerra para alcanzar la gloria con sus hazańas, expresándose un cierto sentido de virtus, que concede buena reputación a los combatientes (10-23). Se trata de un aspecto fundamental de la cultura política y militar, puesto que la virtus se relacionaba con un conjunto de principios y valores asociados a la masculinidad, expresada sobre todo en el campo de batalla?

Esta expansión política y territorial se relaciona con el bellum iustum, es decir, la guerra justa "emprendida en defensa propia o en apoyo de aliados" (Rawson 507). Para Korff, los romanos ven a los pueblos vecinos como inferiores en civilización y cultura, además de hostiles, lo que permite emprender guerras justas para conservar el orden (252). Tal como explica Kakarieka, "el fin de la guerra debe ser la paz; en lo posible, una paz justa y estable" (360).

Roma, salvo situaciones excepcionales, declaraba la guerra todos los

cultural que define sus valores cívicos y vínculos con la patria, lo que fortalece su espíritu imperialista hacia los otros pueblos y genera, según Nieto, "un discurso legitimador sobre sus conquistas, fundamentadas, principalmente, desde una arista civilizadora y justa". En este sentido, los principios de justicia y civilización permiten "construir un discurso sobre el imperialismo romano como legítimo, conllevando que Roma se esforzara por establecer el fundamento de su avance por el orbe desde una dimensión defensiva, cuestión acompañada del efecto romanizador" ( "Ciudadanía..." 100). Sobre el uso de la diplomacia, la legitimación política y el imperialismo romano, véase Nieto, "Diplomacia..." 29-60; Auliard 17-34; Erskine 3-87; Badian 1-15; Burton, Friendship... 1-75 y Roman Imperialism 10-73.

8 La guerra ofrece ganancias económicas, ya sea de tierra, botín, esclavos y rentas, como resultados naturales del triunfo que permiten incrementar el poder (Harris 55).

9 Según Nieto, el concepto virtus alude a la "energía inherente al hombre cuyos efectos sobre la realidad conllevan, al mismo tiempo, la manifestación y la construcción de la masculinidad. Una fuerza indomable que se expresa de forma icónica en el campo de batalla y en las acciones características del hombre, que, como guerrero ejemplar, alcanza la gloria. No responde, empero, a una condición otorgada por la naturaleza sin más; está presente de forma potencial, pero requiere de su desarrollo voluntario. Es, por tanto, un término complejo, por cuanto considera las características que son propias del hombre y de su desempeño militar, demostrando aquello que le es propio, a saber, la valentía, manifestada siempre bajo el estricto control de la razón, facultad propia del espíritu humano" (Nieto, Salustio... 295). Para una mayor revisión sobre la noción de virtus, véase Balmaceda, "Virtus...". 285-304; Balmaceda, Virtus romana 14 y ss.; McDonnell 105-58; y Lendon 247-53. 
años contra los estados vecinos (Harris 9), decisión que tomaba el Senado buscando las razones que justificaran y legitimaran su lucha en beneficio de los romanos (Rich 59-60). Según Garlan, esta declaración de guerra a otros pueblos refleja un despliegue de los recursos del espíritu legalista de Roma (47-50), donde la justificación del combate se asocia con la defensa legítima de la patria, el orden de la república y la civilización romana ${ }^{10}$. Asimismo, la guerra adquiere consideraciones sagradas y religiosas, lo que permite fortalecer la relación de la pietas con los dioses, al igual que el deber cívico, tanto en la protección de su patria y el proceso de expansión política y militar. Los cultos y celebraciones a las divinidades romanas -mediante sacrificios, ofrendas y rituales- buscan mantener una estabilidad y apoyo de sus dioses, de modo que no se enfurecieran y no afectaran negativamente las campañas militares o al Estado romano. Así, la guerra se consolida mediante la piedad con sus divinidades, forjando un vínculo religioso que permita respetar el orden cósmico y las leyes del mundo romano, pues tal como enfatiza Kakarieka, resulta importante "contar con el favor de los dioses, porque el éxito o el fracaso en la guerra dependía, en definitiva, de su voluntad" $(346)^{11}$.

10 La teoría del bellum iustum y del derecho fecial se ponen en práctica como una guerra defensiva, tanto para prevenir ataques contra Roma como para defender a sus aliados. Así, esta guerra preventiva del mundo romano establece una legitimación y justificación de sus acciones, lo que permite que puedan realizar sus guerras de expansión en Oriente y Occidente, articulando una hegemonía del poder (Gabba, "Aspectos culturales..." 231-2).

11 Cabe mencionar que las guerras del mundo romano poseen connotaciones rituales y religiosas, en cuanto se establecen fiestas en los calendarios para "no provocar la ruptura de la pax deorum" (Pérez Frutos 181). Junto con esto, los romanos elevan plegarias y construyen templos y estatuas para sus dioses, tales como Victoria, Marte, Neptuno, Júpiter y Hércules, destacando sus atributos militares. Acuden a ellos cuando desean "expresar su deseo de un dominio aún mayor", para conquistar nuevas tierras y contar con el beneficio de las divinidades (Harris 121). Incluso, en marzo las celebraciones al dios Marte -quien posee "una estrecha relación con el mundo bélico"- tienen por finalidad "la preparación litúrgica del ejército" (Pérez Frutos 182). Para el mundo romano, "Marte es el dios que le protege en la guerra", por lo que realizan rituales y sacrificios para contar con su favor y obtener la victoria en el campo de batalla (Guillén 212). En este sentido, las fiestas militares "tenían como objeto fundamental recordar el deber cívico de la participación en el ejército y despertar el espíritu bélico de los romanos: así como poner bajo la protección de los dioses las futuras acciones 
Ahora bien, las guerras romanas tuvieron diferentes direcciones y resultados: destrucciones de las ciudades enemigas o sometimiento de los pueblos vencidos que implicó nuevos tratados y pactos. Ziolkowski menciona que la direptio es el saqueo a ciertas ciudades, en que los soldados romanos desgarran, destrozan y cometen ultrajes, resaltando el poder y dominio de Roma sobre el pueblo vencido, como resulta ser el caso de Cartago (70 y ss.). Sin embargo, la eliminación física del adversario, tal como aprecia García Riaza, supone un menoscabo económico para los vencedores, pues desaparece "la posibilidad de enriquecerse mediante la venta de los prisioneros" ("Sobre los mecanismos..." 162).

También es posible apreciar operaciones políticas y militares que le permitieron a Roma aprovechar recursos, suministros y riquezas de los pueblos derrotados. La deditio constituye "un acto formal de sometimiento", en la que Roma posee una libre disposición de personas y bienes de la ciudad derrotada $(163-4)^{12}$. Los vencidos se comprometen a pagar la indemnización de la guerra; colaboran logística y militarmente; asumen una libertad condicional y vigilada; y quedan prohibidos los contratos y acuerdos con otras ciudades; finalmente, el Estado romano, al someter a estos pueblos, asume las tareas defensivas de los territorios que se encuentran bajo su soberanía $(165)^{13}$.

Por otra parte, la oppugnatio consistía en un asalto armado, en el que "el concepto de indemnización cedía paso a la represalia", pues, tal como explica Martínez Morcillo, se tomaban medidas que "podían afectar a los bienes de los núcleos rendidos (saqueo, incendio, destrucción, incautación de territorio) y la libertad de sus habitantes, pudiéndose llegar a la aplicación

militares" (Pérez Frutos 182).

12 Hay que tener presente que deditio, con su raíz en de-do, didi, ditum, constituye una 'entrega' y 'rendición; dediticius, a, um, refleja la persona sometida y súbdita (Diccionario Esencial Latino-Español VOX 101).

13 Cabe destacar que "la rendición del adversario (deditio) debe asumir la forma de un tratado que defina, en términos precisos, las relaciones entre el vencedor y el vencido" (Kakarieka 360). Esto abre paso a un tratado de alianza, en el que Roma busca una paz justa y estable, mostrando moderación y benevolencia frente a los vencidos, preservando la existencia de quienes no han sido crueles ni bárbaros en la lucha. 
de castigos físicos, e incluso, la pena de muerte" (140). Según Dillon y Welch, la noción de oppugnatio constituye el saqueo y el asalto realizado por el ejército romano (56-8) ${ }^{14}$. En cierta medida, con la oppugnatio, notamos una relación con la pugna, es decir, la pelea, el combate y el pugnar con otro (Diccionario Esencial Latino-Español VOX 372) y también con la noción de punitio, punire, como castigo y venganza (373). Mediante este sometimiento de poblaciones de asalto directo, "el empleo indiscriminado de la violencia contra personas, animales y propiedades resultaba admisible, y también, desde luego, la esclavización de los prisioneros" (García Riaza, "Las fronteras..." 19) 15 .

En suma, mediante estos mecanismos diplomáticos y bélicos, podemos comprender los modos de articulación del poder de Roma frente a los pueblos vencidos. El mundo romano justificó las guerras con el argumento de la defensa de la patria y su civilización ante cualquier amenaza externa, lo que conllevó la expansión hacia los pueblos adyacentes, conquistando sus territorios y obteniendo botines y riquezas que aportan los suministros del Estado. En esta línea, si bien los estudios historiográficos de la diplomacia romana se enfocan en las dimensiones políticas y jurídicas, examinando las embajadas y relaciones exteriores del mundo antiguo, en el caso de la obra de Apiano, hasta donde hemos investigado, no conocemos trabajos que analicen sistemáticamente las nociones de la deditio y la oppugnatio como instrumentos de guerra. De este modo, la propuesta de nuestro estudio ofrece una revisión de ambos conceptos para comprender la construcción de poder del mundo

\footnotetext{
14 No hay que perder de vista que oppugnatio, onis, es un ataque, sitio o saqueo; opugnator, oris, es el opugnador que ataca y combate; y op-pugno, es atacar, sitiar y asaltar (Diccionario Esencial Latino-Espańol VOX 309).

15 Hay que tener presente que las características de la intervención romana se basan en "la existencia de una serie de actuaciones regladas en caso de asalto de poblaciones, de modo que se establecería una escala de gravedad en función del grado de oposición del enemigo" (Martínez Morcillo, "El asalto...” 119). En otras palabras, los romanos castigan con más o menos fuerza dependiendo las faltas cometidas por los pueblos con quienes tengan conflictos, lo que puede significar un saqueo devastador de las ciudades, incluyendo ultrajes y asesinatos, o bien un asalto de castigo con el cual se impongan condiciones rigurosas de tributos, recursos militares u otros, que deban entregar los pueblos vencidos a los romanos.
} 
romano sobre los pueblos dominados, así como también las diversas relaciones diplomáticas y las prácticas bélicas en los tiempos de crisis y revolución.

\section{Guerras y embajadas romanas en Grecia y Oriente. El PROBLEMA de loS TRATAdos Y LA JUSTIFICACIÓN DE LAS GUERRAS EN TIEMPOS DE LA REVOLUCIÓN ROMANA}

Si nos internamos en el problema de las guerras civiles, notaremos cómo la república romana se encuentra en una fase de crisis. La muerte de Julio César refleja un punto de inflexión, en que los triunviros muestran intereses cada vez más personalistas frente al poder, en tanto que la facción de los republicanos busca restaurar la república. Bajo este contexto de división, ¿qué relaciones se mantienen con las regiones de Grecia y Oriente?, ¿¿de qué manera cada facción envía embajadas al Mediterráneo oriental para contar con su apoyo en la guerra? y ¿en qué medida la ruptura de los tratados por los pueblos sometidos permite a los romanos -triunviros o republicanosjustificar sus guerras?

Si revisamos la situación de Casio, quien mantiene embajadas con los rodios, notaremos cómo critica la posición de Rodas por aliarse con Dolabella:

Mientras realizaban esta operación, enviaron, no obstante, algunos embajadores de Mindo para pedir a Casio que no menospreciara a Rodas, pues la ciudad se había defendido siempre de quienes la habían despreciado, ni tampoco los tratados existentes entre Rodas y Roma, en virtud de los cuales ninguno de los dos pueblos llevaría sus armas contra el otro. Pero que si les reprochaban algún punto relativo a la alianza, querían oírlo de boca del senado romano, y que si este se lo ordenaba afirmaron que contribuirían como aliados. Tales fueron las propuestas de los embajadores rodios. Casio, a su vez, les dijo que en las demás cuestiones decidiría la guerra en vez de las palabras, pero que, en relación con el tratado que prohibía llevar la guerra uno contra otro, lo habían violado los rodios al aliarse con Dolabella frente a Casio. (Apiano IV, 66) 
Podemos notar cómo se anuncia el sentido de una guerra justa, en cuanto los rodios se alían a Dolabella, uno de los enemigos de la república ${ }^{16}$. $\mathrm{Ni}$ rodios ni licios suministran ejércitos a Casio, por el contrario, prestan su apoyo a Dolabella (Apiano IV, 61), esto da cuenta de que los pueblos aliados también toman posiciones políticas por las facciones de las guerras civiles. Esto se torna un motivo fundamental que justifica la guerra de los republicanos contra los rodios, en cuanto consideran que han quebrado los tratados y acuerdos con Roma. Tal como expresa Gabba, se justifica el proceder de Casio dado que los rodios han elegido la causa de los usurpadores y enemigos republicanos (Appiano... 182-4).

Los rodios envían como embajador a Arquelao, para convencer a Casio que no lleve a cabo una guerra en la que los rodios serán totalmente aniquilados, o Casio sufra una derrota. En su ruego, destaca el apoyo dado por los rodios a Roma en la lucha contra Demetrio, Mitrídates y Antíoco el Grande, en defensa de la libertad (Apiano IV, 67) ${ }^{17}$. De manera explícita, recalca el asunto de los tratados:

Vosotros, romanos, jurasteis por los dioses cuando, no hace mucho, renovasteis con nosotros un tratado por medio de Gayo César, y, después del juramento, hicisteis libaciones y tendisteis vuestra mano derecha, signos todos que tienen mucha fuerza incluso entre los enemigos. ¿¿No la van a tener entre amigos y maestros? Y, además de los dioses, salvaguardad vuestra reputación ante los hombres, pues nada hay peor que la violación de un tratado, acción que provoca el descrédito total de sus agresores ante los ojos de los amigos y de los enemigos. (Apiano IV, 68)

16 Según Mackay, Dolabella al vencer a Trebonio, uno de los conspiradores de César, y derrocarlo como gobernador de Asia, genera resquemores en el círculo de los republicanos, dado que busca vengar al dictador. Bajo este contexto, Cicerón declara enemigo público a Dolabella, por lo cual, Casio está encargado de perseguirlo y vencerlo, como una manera de acabar con los enemigos de la república (379-80).

17 El argumento del embajador rodio recuerda el constante amor a la patria y la libertad, dando a entender que Roma tiene una deuda con los rodios por toda la ayuda prestada para que los romanos vencieran en sus batallas. Arquelao insta a que no olvide los pactos jurados (Gabba, Appiano... 183). 
El cumplimiento de los tratados constituye un aspecto clave que define las relaciones internacionales, que incluso se consagra ante los dioses. La violación de un tratado es un acto impío que provoca descrédito en quienes incumplen los acuerdos. Para Kakarieka, hay un sentido de honor plasmado en el respeto del tratado o pacto y que, en el caso de la costumbre romana, debe cumplirse íntegramente, ya sea tanto con sus amigos, aliados o enemigos (353). De hecho, quien quebranta "su promesa o juramento, aunque no se expusiera a ninguna clase de sanciones legales, cometía una falta grave contra el sentido del honor" (Kakarieka, 353). En este sentido, violar un tratado puede dañar la reputación de quien lo haga, generando una ignominia y degradación por faltar a las normas éticas y honorabilidad.

Ahora bien, Casio defiende su postura y juzga a los rodios culpables de haber traicionado a Roma:

Si tú no aconsejaste a los rodios que no me hicieran agravio, tú mismo me lo hiciste [...] En primer lugar, cuando os pedí ayuda y fui ignorado por quienes eran mis educadores y tutores $y$, por segunda vez consecutiva, cuando dieron preferencia sobre mí a Dolabella, al que ni educaron ni criaron; pero lo peor de todo, oh rodios, amantes de la libertad, es que yo, y Bruto, y cuantos miembros preclaros del senado tenéis ante vuestros ojos, éramos fugitivos de la tiranía y tratábamos de liberar a nuestra patria, mientras que Dolabella quería hacerla esclava de otros, aquellos, precisamente, a los que antes habéis ayudado, y pretendéis ahora querer absteneros de nuestras guerras civiles. Esta, en efecto, sería una guerra civil si nosotros aspirásemos al poder absoluto también, pero es evidente que se trata de una guerra entre la República contra la Monarquía. (Apiano IV, 69)

Casio define que esta guerra se debe a factores políticos y en ella se lucha contra el poder personal y monárquico. Todo opositor a la república debe ser castigado. En este sentido, Casio considera a los rodios como los traidores a Roma, al apoyar a las fuerzas enemigas de Dolabella. De hecho, 
los mismos rodios atacan de manera traicionera a los romanos, siendo finalmente derrotados ${ }^{18}$. Roma concibe atacar y castigar a los rodios como una causa justa, que tiene un carácter aleccionador para el pueblo sedicioso y, al mismo tiempo, busca obtener ventajas económicas -suministros y riquezas- como parte del botín de guerra. El mismo Apiano nos relata: "Así fue tomada Rodas, y Casio se sentó sobre el tribunal y clavó la lanza a su lado para indicar que había sido tomada por la fuerza" (Apiano IV, 73). La fuerza militar era justificada por la violación de los tratados por parte de los rodios, siendo utilizada como una herramienta de legitimación de la conquista romana (Galindo Roldán 206) ${ }^{19}$.

Para Casio, como defensor de los intereses del senado y la república, el objetivo de la lucha es acabar con todo partidario de César, que tienda hacia el poder monárquico y persona ${ }^{20}$. Tal como narra Apiano, en palabras de Casio, se considera que César atenta "contra les leyes y el ordenamiento constitucional” (IV, 91). Así, la guerra contra los cesarianos, o bien sus aliados, es justa en cuanto no se tolera que instale un poder real, donde solo una persona concentre el poder en sus manos; es una guerra en contra

18 "Los navíos rodios fueron capturados con sus tripulaciones, dos fueron perforados y se hundieron y los restantes huyeron averiados a Rodas" (Apiano IV, 71)

19 Tal como expresa Dionisio de Halicarnaso (60 a. C.-7 a. C.), los romanos deben cuidarse de emprender guerras injustas, por lo cual, si los otros estados aliados incumplen los tratados o acuerdos, recién en ese momento se pueden iniciar las hostilidades. En sus palabras, se debe "cuidar que los romanos no emprendan ninguna guerra injusta contra una ciudad aliada; si otros inician la violación de los tratados, enviar embajadores y en primer lugar pedir verbalmente explicaciones, y si no escuchan sus peticiones, entonces declarar la guerra. De la misma manera si algunos aliados afirman haber sufrido injurias de los romanos y piden justicia, estos hombres determinan si han sufrido algún daño contra los tratados, y si les parece que demandan lo justo, detienen a los acusados y se los entregan a los afectados. Juzgan también los delitos cometidos contra los embajadores, vigilan que se respeten sagradamente las cláusulas de los tratados, firman la paz y anulan la ya existente, si les parece que no se ha hecho según las leyes sagradas; juzgan los delitos de los generales que tenían relación con juramentos y tratados y los purifican” (Historia antigua de Roma, II, 72, 4-5). En otras palabras, el violar un tratado o acuerdo con los romanos constituye causa suficiente para que estos puedan tomar represalias y realizar una guerra justa en defensa de sus intereses.

20 Jal sostiene que Casio hace ver a los rodios que él no intenta, como sus oponentes, tomar el poder supremo, por lo cual concibe que esta guerra civil es una lucha de la democracia contra la monarquía (456). 
de la tiranía, es decir, acabar con los triunviros considerados criminales por provocar caos en el orden institucional (Apiano IV, 95-7).

Por otra parte, cuando Antonio se reúne con Cleopatra en Cilicia, le reprocha no haber participado de la lucha para vengar a César, ante lo cual ella responde que sí cumplió como aliada, enumerando sus acciones en favor de Antonio:

Ella, en cambio, en lugar de defenderse, pasó a enumerar lo que había hecho diciendo que había enviado de inmediato a Dolabella las cuatro legiones que tenía consigo [...] Pero que no se había aliado con Casio, el cual la había amenazado por dos veces, y que, a pesar de la hostilidad de aquellos, se había hecho a la mar rumbo al Adriático con una flota muy poderosa sin temer a Casio. (Apiano V, 8)

Cleopatra, reina de Egipto y aliada de Antonio, muestra su fidelidad a través de acciones concretas en la guerra contra los republicanos. Incluso, destaca su lealtad ante la amenaza y hostilidad de Casio. La lealtad de Cleopatra no constituye un acto que deba ser castigado. Ahora bien, es importante señalar que cada facción aprecia en los estados orientales la posibilidad de beneficiarse con sus alianzas, sobre todo contar con su apoyo militar que, tal como estima Syme, es un estado vasallo al servicio del gobierno y la defensa que no está conectado "por ningún principio de uniformidad", sino que depende "de vínculos de alianza personal" (320). De este modo, la alianza de Antonio con Cleopatra permite al triunviro contar con una tierra rica en suministros económicos y militares que puedan favorecer sus intereses en la consecución del poder y para vencer a sus enemigos ${ }^{21}$.

Antonio considera justo tomar venganza contra los partos:

$21 \quad$ Cabe destacar que Antonio espera "obtener dinero y abastecimiento para sus empresas militares" de su alianza egipcia. Egipto constituye "la más valiosa de sus reservas", pues comprende una "cadena de reinos que llegaba por el norte hasta el Ponto y por el oeste hasta Tracia y protegía por el frente y por el flanco las provincias romanas de Siria, Bitinia, Asia y Macedonia” (Syme 320). 
Y Antonio lucharía contra los partos para vengar la traición que cometieron con Craso [...] Y, al punto, cada uno envió a sus amigos a ocuparse de los asuntos más urgentes, Antonio envió a Ventidio a Asia para sojuzgar a los partos y a Labieno, el hijo de Labieno, quien, junto con los partos, había hecho incursiones en Siria y en la zona de Asia que se extiende hasta Jonia, durante estas últimas conmociones. (Apiano V, 65)

Antonio envía un ejército liderado por Ventidio para someter a los partos, que amenazan la frontera oriental de Roma. Resulta justo luchar contra ellos, puesto que traicionaron a Craso en el año 53 a. C., haciéndolo caer en una trampa y derrotándolo en la batalla de Carras, la que le costó su vida y la de la mayor parte de su ejército (Mattern-Parkes 387-96; Lane Fox 743). Asimismo, realizaron diversas incursiones en Siria y las provincias cercanas a Jonia. De esto, Apiano narra que Casio en el 43 a. C., había enviado de regreso "a los arqueros partos, con regalos, y despachó embajadores al rey de estos para solicitar un número mayor de tropas auxiliares" (IV, 60). Estas tropas llegaron después del combate "e hicieron incursiones por Siria y muchas provincias de las provincias vecinas hasta Jonia y se retiraron" (IV, 60). En cierta medida, estos sucesos, de los cuales Antonio tenía conocimiento, fundamentan las causas que justifican emprender una lucha contra los partos, como enemigos de la frontera romana de Siria y Palestina ${ }^{22}$.

En suma, podemos considerar que las embajadas romanas republicanas o cesarianas -Casio y Antonio, respectivamente-a Grecia y Oriente muestran las relaciones internacionales establecidas con las ciudades aliadas, que se constituyen en un gran aporte en términos políticos, económicos y militares para el mundo romano. Ahora bien, el comportamiento de cada ciudad

22 Precisamente, Ventidio es enviado para combatir contra Labieno y Pacoro en la provincia de Asia, donde obtuvo victorias importantes y recuperó territorios que consolidaron la frontera romana oriental. En el 39 a.C. derrotó a Labieno en tres batallas en Asia menor. El 38 a.C., Ventidio venció a Pacoro y lo mató en la batalla de Gindaros, al norte de Mesopotamia. La muerte de Pacoro y la destrucción de su ejército fue considerado por los romanos como un duro golpe para los partos, y una victoria romana que redimió la desgracia de Carras (Seaver 277 y ss.; Mackay, 402-3). 
aliada, ya sea favorable o no a los intereses de los defensores de la república o los triunviros, determina el tratamiento que le otorga Roma. Cada facción busca contar con el apoyo de las ciudades aliadas y en caso de no ser así, los romanos consideran justo declarar la guerra contra esos estados con la finalidad de poder desarticular sus fuerzas y disminuir el poder del enemigo.

\section{LAS PRÁCTICAS BÉLICAS Y LOS DERECHOS DE GUERRA DE RoMA CON LOS PUEBlos VENCIDOS: LA DEDITIO Y LA OPPUGNATIO COMO INSTRUMENTOS DE GUERRA Y PODER}

Si examinamos las relaciones que mantiene Roma con los pueblos vencidos de Grecia y Oriente, apreciaremos ciertos mecanismos de guerra e instrumentos de sometimiento que consolidan su poder para obtener diferentes tipos de recursos económicos y militares que financian la lucha de cada facción. En la batalla contra Dolabella en el 43 a. C., notaremos que contó con el apoyo de ciudades que le entregaron diversos recursos militares:

Dolabella pasaba el tiempo en Jonia, donde dio muerte a Trebonio, impuso tributo a las ciudades y, por medio de Lucio Fígulo, alquiló una flota a los rodios, licios, panfilios y cilicios [...] Informado de las fuerzas de Casio, prosiguió hasta Laodicea, ciudad amiga suya y situada en una península, que estaba bien fortificada por el lado de la tierra y tenía un puerto desde el que podría procurarse alimentos con facilidad por vía marítima. (Apiano IV, 60)

O el caso de Bruto que cuenta con apoyo de los licios: "La confederación licia envió embajadores de Bruto prometiéndole aliarse con él y aportar dinero que pudieran" (Apiano IV, 82).

En ambos pasajes podemos observar cómo la facción republicana dispone de apoyo de las ciudades aliadas. En el primer caso, Dolabella suma recursos militares -flota marítima- y suministros logísticos -alimentos 
para los ejércitos-. Junto con eso, Bruto cuenta con aliados que le aportan dinero $^{23}$. Las ciudades aliadas constituyen una fuente de recursos para sostener la guerra. Roma concibe a Asia como una fuente de suministros (Bertrand 697). La prosperidad romana depende en gran medida de las riquezas y recursos griegos y orientales, pues se benefician con la exportación de soldados, recursos financieros y materiales, entre otros $(705)^{24}$.

El mundo romano se expande por Grecia y Oriente con la finalidad de disponer de más recursos que financien sus guerras. Casio tras vencer a Dolabella, castiga a Laodicea por su apoyo al enemigo público:

Después de que la ciudad fue tomada, Dolabella presentó su cabeza a su centinela personal, y le ordenó que la cortara y se la llevara a Casio como su propio salvoconducto. Él se la cortó y se degolló a continuación, y también se suicidó Marso. Casio hizo prestar un nuevo juramento de fidelidad a su persona al ejército de Dolabella, saqueó los templos y el tesoro público de Laodicea, castigó a los ciudadanos más ilustres e impuso fuertes tributos al resto hasta que la ciudad quedó reducida a extrema miseria. (Apiano IV, 62)

Asimismo, se castiga al pueblo de Tarso:

23 Plutarco relata cómo los pueblos griegos aportan recursos a Roma, como es el caso de los licios: "Bruto, por su parte, reclamaba de los licios dinero y tropas" (Vidas paralelas, Bruto, 30, 4, 367). Asimismo, se señala cómo a los rodios se les obliga a entregar recursos a los romanos: "Casio obligaba a los rodios a entregarle cuanto oro y plata poseían, del que se recogieron unos ocho mil talentos, e imponía al erario público una multa de otros quinientos talentos" $(32,4,369)$.

24 Podemos destacar cómo Bruto y Casio, en el momento que combaten contra las fuerzas de Octavio y Antonio, esperan agotar las provisiones de los enemigos, con la finalidad de derrotarlos por desgaste y falta de alimentos. De esto, Apiano nos describe Oriente según Bruto y Casio: "Ya que ellos tenían a Asia por despensa y todo se lo hacían llevar por vía marítima desde muy cerca, en tanto que los enemigos no tenían nada en abundancia ni en su propio territorio" (IV, 108). En otras palabras, Asia constituye un espacio de recursos y suministros que permite otorgar riquezas, abundancia y prosperidad al mundo romano, reflejando una verdadera despensa de recursos militares y económicos con los que sostienen la guerra. 
Casio, después de su victoria sobre Dolabella, les impuso un tributo de mil quinientos talentos. Ante la falta de recursos y la exigencia violenta del dinero por los soldados, vendieron el tesoro público en su totalidad y, después, acuñaron en moneda todos los objetos sagrados destinados a las procesiones y las ofrendas. Puesto que no se completaba la suma total con ninguna partida, los magistrados procedieron a la venta de los ciudadanos libres, primero las doncellas y los niños, y después las mujeres y los ancianos, comprados a un precio muy bajo, y finalmente los jóvenes. La mayoría de ellos se suicidaron. (Apiano IV, 64)

Casio ordena castigar a las ciudades de Laodicea y Tarso, porque es justo sancionar a los aliados de sus enemigos. En ambos casos, podemos notar cómo se aplica la oppugnatio, en cuanto se saquea los templos y el tesoro público, imponiendo fuertes tributos que arruinan a la ciudad. Incluso, en Tarso se vende a los ciudadanos, con el objetivo de disponer de más dinero para las campañas militares. Tal como explica Bertrand, Casio no muestra benevolencia con quienes obedecieron las órdenes de Dolabella, saqueando y sometiendo a duros impuestos a las ciudades derrotadas. La naturaleza del conflicto obliga a desproveer al enemigo, motivo que impulsa a Casio a saquear sistemáticamente el Peloponeso $(697)^{25}$. En el momento que Casio toma Rodas, castiga fuertemente a sus ciudadanos:

25 Cicerón, respecto del castigo y la guerra justa, relata que "Hay también algunas obligaciones que guardar en orden a aquellos de quienes hemos recibido alguna injuria. Porque el castigo y la venganza han de tener sus términos. Y aún no sé si bastará que el que ha hecho la ofensa se arrepienta de ella, así para que él no vuelva a cometer semejante delito, como para que se contengan los demás. Deben guardarse en la República con suma exactitud de los derechos de la guerra. Porque habiendo dos maneras de contender, una por la disputa y otra por la violencia, de las cuales la primera es propia de los hombres, y la segunda de las fieras; se ha de recurrir a la segunda cuando se no pueda usar la primera. Y así se han de emprender las guerras por vivir en una paz segura" (Los oficios o los deberes, I, XI, 17). En otras palabras, se usa la guerra como un recurso para conservar la paz en el mundo romano, sobre todo cuando los enemigos cometen injurias, traiciones o acciones hostiles contra Roma, la justificación de la defensa legítima y la violencia para castigar a sus enemigos y mantener el orden del imperio. 
Dio órdenes estrictas de que el ejército permaneciera tranquilo y proclamó por medio de un heraldo la pena de muerte para aquel que saqueara o cometiera alguna violencia; él mismo citó nominalmente a cincuenta ciudadanos rodios $\mathrm{y}$, cuando fueron conducidos a su presencia, los castigó con la muerte. A otros, aproximadamente veinticinco, que no fueron encontrados, ordenó que fueran desterrados. Expolió cuanto dinero, en oro o plata, había en los templos y en el tesoro público. (Apiano IV, 73)

Podemos notar cómo se establece un duro castigo a los rodios por su traición a la república de Roma. Para Combes, "la ley de la guerra, en el mundo antiguo, otorga al vencedor el derecho de disponer a su gusto del vencido; puede destruir o esclavizar a los seres humanos y apropiarse de todos sus bienes" (136-7). En el castigo a los rodios se aplicó la oppugnatio como una forma de saqueo en la que se sancionó fuertemente a los vencidos, con la finalidad de mostrar la imagen de poder de facto de los romanos. De hecho, estos toman el dinero, en oro y plata, de los templos y arcas fiscales. En cierta medida, podemos considerar esta práctica como parte del ius in bello, en el que se establece "un sometimiento total del vencido a los derechos del vencedor" (BuonoCore, "Guerra y diplomacia..." 97).

Antonio también se dirige a los pueblos de Grecia, mencionando que apoyaron a los asesinos de César, a pesar de que este había sido benevolente con los griegos:

Y a quien no tuvo un comportamiento tal nuestros ciudadanos honorables lo llamaron tirano, y vosotros les ayudasteis con grandes sumas de dinero a ellos que eran los asesinos de vuestro bienhechor y en contra de nosotros que perseguíamos su venganza. Sin embargo, como la justa fortuna sentenció la guerra no en el sentido que vosotros queríais, sino como debía ser, si fuera necesario trataros como a unos aliados de nuestros enemigos habría que castigaros, pero, puesto que creemos voluntariamente que vosotros habéis actuado así en virtud de una fuerza mayor, os eximimos de las penas más severas, 
mas necesitamos dinero, tierra y ciudades como premios para la victoria de nuestros ejércitos. (Apiano V, 4-5)

Antonio solicita el apoyo de los griegos para financiar la guerra con recursos de dinero, tierras y ciudades. Los romanos aplican la deditio como un instrumento en el que el pueblo aliado debe retribuir económica y militarmente al poder dominante. Para Roma, es justo solicitar ayuda a los aliados de sus enemigos ${ }^{26}$. En este caso, Antonio les perdona las faltas a los griegos, considerando que habían apoyado a los asesinos de César. Ahora bien, en vez de destruir y saquear sus tierras, les ofrece una solución: los pueblos vencidos deben entregar tributos y recursos como una manera de compensar sus faltas ${ }^{27}$.

Con el recurso de la deditio se aprecia una relativa compasión por parte de Roma:

Los griegos, mientras él estaba hablando, se arrojaban contra el suelo y alegaron en su defensa la coacción y la violencia ejercida contra ellos por Bruto y Casio, y que no se merecían castigo, sino compasión [...] Finalmente, ante la insistencia de sus ruegos, consiguieron rebajar la cantidad de nueve años pagaderas en dos [...] Dio un respiro a las ciudades que habían sufrido más severamente, y así eximió del pago de los tributos a los licios, impulsó la reconstrucción de Janto y dio a los rodios Andros, Tenos, Naxos y Mindo [...] Otorgó la libertad a las ciudades de Laodicea y Tarso y las eximió del pago de tributos, y a los

26 Antonio y Octavio vencen en la batalla de Filipos a los ejércitos de Bruto y Casio en el 42 a. C. El éxito de la guerra obliga a restablecer la situación de Oriente, recibiendo la lealtad y las excusas de las ciudades y los reyes que apoyaron a los republicanos, como también someter cualquier oposición que quedara y recaudar dinero de sus ciudades sometidas y aliadas (Alston 161; Gómez Pantoja 507). En esta línea, los griegos, aliados de Roma, están obligados a prestar servicios de amistad, lo que implica que los gastos recaen sobre los pueblos administrados por el mundo romano a través del hospitium o de las confiscaciones (Bertrand 679).

27 Tal como menciona Apiano, Antonio en su avance por Frigia, Misia, Galacia de Asia, Capadocia, Cilicia, Cele-Siria, Palestina, Iturea, y las demás regiones de Siria, impuso también fuertes contribuciones $(\mathrm{V}, 7)$. 
habitantes de esta última, que habían sido vendidos como esclavos, los liberó de la esclavitud mediante un edicto. (Apiano V, 6-7).

\section{Mediante la deditio notamos cómo los pueblos vencidos se encuentran} sometidos a la soberanía romana, aportando recursos de guerra, ejércitos y dinero, obteniendo a cambio protección y seguridad por parte de Roma ${ }^{28}$. García Riaza señala que Roma puede "aplicar a los dediticii cualquier tipo de sanción o represalia”, sin embargo, la idea de rendición y la solicitud de clemencia por los vencidos, limita al máximo las agresiones físicas y solo solicitan aportes económicos y militares (“Sobre los mecanismos...” 164). Esta suerte de compasión es una de las virtudes romanas que muestra la piedad y humanidad, pues hace disminuir las cargas tributarias ${ }^{29}$. Roma exime de pagos a los pueblos más dańados, impulsa reconstrucciones y libera de la esclavitud. La deditio que aplica Antonio a los pueblos griegos establece una alianza, en que las ciudades aliadas aportan recursos a Roma y el triunviro las resguarda ${ }^{30}$.

28 Cabe mencionar que Roma convierte a los pueblos vencidos en socii, es decir, "aliados", colocándolos en una situación de inferioridad que les obliga a obedecer al vencedor. Ahora bien, Roma le impone a título de compensación por su protección, "impuestos parecidos a las contribuciones de guerra fijadas por los tratados, si bien en este caso permanentes, y levas de tropas destinadas a crear cuerpos de 'auxiliares'”(Combes 137).

29 El sentido de la piedad, clemencia o compasión, son aspectos recurrentes en la narrativa de Apiano, y que tratan de mostrar una imagen de Roma benevolente, como padre, que cuida también a los suyos. Cuando Bruto ataca a los jantios y estos se empiezan a suicidar, apreciamos: "Tras la captura de la ciudad, los jantios se agruparon en el interior de sus casas, mataron a sus seres más queridos que se ofrecieron voluntariamente para ser asesinados. Cuando se alzaron los gritos de lamento, Bruto pensó que había empezado el saqueo y ordenó al ejército que lo interrumpiera, por medio de heraldos. Pero, tan pronto como se enteró de lo que ocurría, se apiadó del espíritu amante de la libertad de tales hombres y envió emisarios para ofrecerles propuestas de paz" (Apiano IV, 80). Hay un sentido de piedad que se manifiesta, donde los romanos buscan ofrecer la paz a los pueblos vencidos. El concepto de paz dentro del mundo romano significa un acuerdo, es decir, esta considera tratados para prevenir o terminar una guerra, reflejando condiciones pacíficas que se oponen a una hostilidad. De hecho, tal como sostiene Woolf, la paz constata un estado de orden y seguridad, sobre todo en las provincias y fronteras de su territorio (176 y ss.).

30 Tal como sostiene Nicolet, la fides romana es una relación recíproca que considera "obligaciones de clemencia, protección y moderación por parte del vencedor" (749). 
En el momento que Bruto toma la ciudad de Patara, notamos:

Al día siguiente se presentó con el ejército. Los habitantes gritaron desde las murallas que le obedecerían en lo que quisiera y le abrieron las puertas. Bruto, tras entrar en la ciudad, no expulsó ni mató a nadie, pero reunió el oro y la plata que poseía la ciudad y ordenó que cada ciudadano trajera su propio peculio, bajo la amenaza de los castigos y recompensas que Casio había promulgado en Rodas. (Apiano IV, 81)

Bruto tras tomar la ciudad no expulsa ni asesina a nadie, más bien está interesado en los recursos económicos que puede recaudar para financiar su guerra. Podemos apreciar la noción de la deditio, en cuanto no es un ataque violento contra la ciudad, pero sí expresa amenazas de castigos si no se cumplen las órdenes o recompensas en caso de que sean aliados leales a Roma. Según Buono-Core, desde el punto de vista jurídico, la deditio no constituye "la extinción de la comunidad, sino la transferencia de poder y la disposición de un modo absoluto, de todos los elementos jurídicos y materiales". En este sentido, el pueblo en condición de deditio queda bajo el poder de Roma, tanto en su soberanía, tierra y personas, además de entregar armas, rehenes y pagar los costos de la guerra ("Guerra y diplomacia..." 98-9). No obstante, Roma puede conceder beneficios también a sus aliados, en la medida que ayuden a sus intereses, lo que finalmente se expresa en la protección romana a los pueblos sometidos.

En suma, podemos considerar que en la obra de Apiano se habla de la deditio y la oppugnatio, como instrumentos de guerra para someter y castigar a los pueblos vencidos. Así, la guerra toma un cariz de lucha justa, en cuanto se sanciona a los aliados y enemigos dependiendo de sus faltas y se impone la fuerza contra los pueblos derrotados como un modo de articular una imagen de poder de Roma, ya sea tanto por parte de los triunviros o republicanos. 


\section{Algunas consideraciones finales}

En la narración de Apiano se mencionan prácticas y derechos de guerra a partir de embajadas entre Roma y los pueblos griegos y orientales. En el contexto de las guerras civiles, estos pueblos sometidos constituyen una fuente de suministros clave-militares y logísticos- para financiar las guerras de Roma, lo que permite a los republicanos y triunviros sostener sus luchas con fines particulares.

El problema analizado considera la situación de los pueblos aliados y las prácticas de los romanos con estos. En cierta medida, esto considera el respeto de los acuerdos y tratados por ambas partes, implica que los pueblos aliados deben retribuir económica y militarmente a Roma, y esta última proteger a dichos estados. En caso de que los pueblos aliados violen los tratados, Roma puede actuar conforme al derecho y aplicar la guerra justa contra ellos, efectuando la direptio, como saqueo y destrucción del pueblo derrotado; la deditio, como sometimiento del pueblo vencido, ofreciendo ciertas garantías y libertades, en las cuales los subyugados deben aportar recursos a los romanos y estos últimos proteger a sus aliados; $y$, finalmente, la oppugnatio, como un sometimiento violento a los pueblos que han quebrantado acuerdos o han sido hostiles con Roma, siendo sometidos a la fuerza y recibiendo duros castigos, como pago de tributos, entrega de recursos militares y botín de guerra.

En el caso de las guerras civiles narradas por Apiano, apreciamos cómo se describen situaciones de deditio y oppugnatio, que constituyen recursos de guerra que muestran la práctica bélica de Roma con los pueblos derrotados. Hay que señalar que la direptio no es considerada, dado que la destrucción total de un pueblo conllevaría al menoscabo de recursos, y en el contexto de las discordias civiles, es fundamental contar con apoyo de los pueblos aliados y sometidos, por lo que resulta más conveniente someter a los pueblos y establecer cargas y tributos que permitan financiar las guerras.

Bruto y Casio como republicanos, o bien Antonio como un triunviro, acuden a los pueblos griegos y orientales para contar con su apoyo y financiar las empresas bélicas. Ambas facciones utilizan la deditio y oppugnatio 
como parte del modo de hacer la guerra de y una práctica que se concibe cotidiana, de la que los romanos están acostumbrados, en términos que les concede suministros y recursos. Así, tanto triunviros y republicanos usan estos recursos con la finalidad de poder consolidar acuerdos y estrategias que los favorezcan en escenarios de batallas y proporcionen riquezas y abastecimientos para sostener la lucha.

Por otra parte, si bien la deditio y oppugnatio constituyen sometimientos a los pueblos vencidos, también reflejan instrumentos de guerra y poder que ensalzan la imagen de dominio y potestad de Roma. En el contexto de guerras civiles, en que triunviros y republicanos combaten por alcanzar el poder, se apoyan en estos instrumentos de guerra para fortalecer su propia imagen de poder y dominio sobre los territorios subyugados. Tanto Bruto y Casio que buscan conservar el poder de la república y evitar que se instale un poder personal y monárquico, someten a los griegos con la finalidad de contar con sus recursos y triunfar contra los partidarios de César. Por su parte, Antonio establece alianzas con pueblos griegos y orientales, con el propósito de ensalzar su poder y establecer un dominio personal sobre el territorio oriental del mundo romano ${ }^{31}$.

En definitiva, podemos notar cómo Roma articula las prácticas bélicas y los derechos de guerra en torno a la tradición militar de autodefensa e imperialismo, con la cual ensalza su imagen de poder por sobre los pueblos derrotados, y obtiene recursos materiales y económicos de los territorios sometidos. Las facciones de la guerra civil se consolidan, apoyándose de la práctica jurídica de la guerra que permite justificar sus empresas militares, declarando la guerra cuando sus aliados violan acuerdos y tratados, o son hostiles al mundo romano. En cierta medida, el problema no son los acuerdos en sí, sino la necesidad logística de contar con recursos para seguir financiando la guerra, por lo que triunviros y republicanos aprovechan -mediante estas

31 Incluso, mediante estos asaltos y sometimientos a los pueblos griegos y orientales, se aprecia una estrategia de guerra por parte de los romanos, ya sean triunviros o republicanos, en cuanto cada facción intenta desarticular a la otra restándole aliados para obtener recursos. En este sentido, solicitar recursos militares o aplicar fuertes cargas tributarias, deja en una situación de desabastecimiento a los pueblos aliados o sometidos, con lo cual se intenta que potencialmente no favorezcan a sus enemigos. 
rupturas diplomáticas - un nicho que permita someter a los estados griegos y orientales para que proporcionen los suministros necesarios de la guerra, como también para la defensa de los proyectos personales de cada facción de la revolución romana. 


\section{Bibliografía}

Alston, Richard. Rome's Revolution. Death of the Republic and Birth of the Empire. Oxford: Oxford UP, 2015.

Apiano. Historia romana. Guerras civiles. Libros III-V. Traducido por Antonio Sancho Royo. Madrid: Gredos, 1985.

Auliard, Claudine. La Diplomatie Romaine. L'autre Instrument de la conquête, de la fondation à la fin des Guerres Samnites (755-290 av. J.-C.). Rennes: PUR, 2006.

Badian, Ernst. Roman Imperialism in the Late Republic. Oxford: Basil Blackwell, 1968.

Balmaceda, Catalina. "Virtus romana en el siglo I a. C.". Gerión, vol. 25, n. ${ }^{\circ}$ 1, 2007, pp. 285-303.

- $\quad$ Virtus Romana. Politics and Morality in the Roman Historians. Chapel Hill: The University of North Carolina Press, 2017.

Bancalari, Alejandro. "Los aliados y la ciudadanía romana". Revista de Historia Universal, n. ${ }^{\circ}$ 9, 1988, pp. 7-22.

Bertrand, J. Michael. "Roma y el Mediterráneo oriental en el siglo I a. de J.C.". Roma y la conquista del mundo mediterráneo. Editado por Claude Nicolet. Barcelona: Labor, 1984.

Breed, Brian W. y otros. Citizens of Discord. Rome and its Civil Wars. Oxford: Oxford UP, 2010.

Bucher, Gregory. "The Origins, Program and Composition of Appian's Roman History". Transactions of the American Philological Association, vol. 130, 2000, pp. 411-58.

Buono-Core, Raúl. "Guerra y diplomacia en la Roma republicana". Revista de Estudios Histórico-Jurídicos, n. ${ }^{\circ}$ 37, 2015, pp. 93-107.

_. $\quad$ "Los tratados en el mundo romano". Revista de Estudios Históricos-Jurídicos, n. ${ }^{\circ} 25,2003$, pp. 23-34.

_. Roma republicana: estrategias, expansión y dominios (525-31 a.C.). Valparaíso: Ediciones Universitarias de Valparaíso, 2002.

Burton, Paul. Friendship and Empire. Roman Diplomacy and Imperialism in the Middle Republic (353-146 BC). Cambridge: Cambridge UP, 2011. 
_. Roman Imperialism. Leiden, Boston: Brill, 2019.

Cicerón. Los oficios o los deberes. Traducido por Manuel de Valbuena. México D. F.: Porrúa, 2012.

Combes, Robert. La república de Roma. Madrid: EDAF, 1977.

Diccionario Esencial Latino-Español VOX. Barcelona: Larousse Editorial, 2010.

Dillon, Sheila y Katherine E. Welch. Representations of War in Ancient Rome. Cambridge: Cambridge UP, 2006.

Dionisio de Halicarnaso. Historia Antigua de Roma. Traducido por Elvira Jiménez y Ester Sánchez. Madrid: Gredos, 1984.

Eilers, Claude. Diplomats and Diplomacy in the Roman World. Leiden y Boston: Brill, 2009.

Erskine, Andrew. Roman Imperialism. Debates and Documents in Ancient History. Edinburgh: Edinburgh UP, 2010.

Gabba, Emilio. Appiano e la storia delle guerre civile. Firenze: La Nuova Italia, 1956.

_. "Aspectos culturales del imperialismo romano". Sociedad y politica en la Roma republicana (siglos III-I a. C.). Pisa: Pacini Editore, 2000, pp. 222-6.

Galindo Roldán, Juan Manuel. "Los tratados y la diplomacia en la Antigüedad: el derecho internacional como sustento de la conquista romana”. Lecciones y Ensayos, n. ${ }^{\circ}$ 91, 2013, pp. 201-8.

García Riaza, Enrique. "Las fronteras de la ley. Servio Sulpicio Galba y el gobierno provincial de Hispania”. La corrupción en el mundo romano. Editado por G. Bravo y R. González Salinero. Madrid: Signifer Libros, 2008, pp. 17-26.

_. "Sobre los mecanismos de integración de los vencidos en el Occidente romano-republicano. Algunas observaciones”. Vae victis! Perdedores en el mundo antiguo. Francisco Marco y otros. Barcelona: Colección Instrumenta 40, 2012, pp. $161-76$

Garlan, Yvon. War in the Ancient World. A Social History. Londres: Chatto \& Windus, 1975.

Gómez Pantoja, Joaquín. “Orígenes y desarrollo del régimen imperial. De los Idus de Marzo al 'año de los cuatro emperadores'”. Historia antigua (Grecia y Roma). Coordinado por Joaquín Gómez Pantoja. Barcelona: Ariel, 2003, pp. 501-45 
Guillén, José. Urbs Roma. Vida y costumbres de los romanos. III. Religión y Ejército. Salamanca: Sígueme, 1994.

Harris, William. Guerra e imperialismo en la república romana, 327-70 a. C. Madrid: Siglo XXI, 1989.

Jal, Paul. La Guerre Civile. Étude Littéraire et Morale. París: Presses Universitaires de France, 1963.

Kakarieka, Julius. "Los orígenes de la doctrina de la guerra justa. Cicerón y la tradición romana". Semanas de Estudios Romanos, Pontificia Universidad Católica de Valparaíso, vol. 15, 2010.

Korff, Baron S. A. "An Introduction to the History of International Law". The American Journal of International Law, vol. 18, n. ${ }^{\circ}$ 2, 1924, pp. 246-59.

Lane Fox, Robin. El mundo clásico. La epopeya de Grecia y Roma. Barcelona: Crítica, 2005.

Lendon, Jon. E. Soldados y fantasmas. Mito y tradición en la Antigüedad clásica. Barcelona: Ariel, 2011.

Mackay, Cristopher S. El declive de la república romana. De la oligarquía al imperio. Barcelona: Ariel, 2011

Martínez Morcillo, José Antonio. "Acabar con la identidad del enemigo: política romana de reorganización de territorios sometidos en contexto de guerra (s. II a. C.)". Historia, identidad y alteridad. Actas del III Congreso Interdisciplinar de Jóvenes Historiadores. Coordinado por José Manuel Aldea Celada y otros. España: Salamanca, 2012, pp. 169-88

_. "El asalto de núcleos de población: bases jurídicas, procedimiento y consecuencias durante la república romana”. Espacio, Tiempo y Forma, Serie II, Historia Antigua, n. ${ }^{\circ}$ 26, 2013, pp. 107-22.

Mattern-Parkes, Susan P. "The Defeat of Crassus and the Just War". The Classical World, vol. 96, n. ${ }^{\circ}$ 4, 2003, pp. 387-96.

McDonnell, Myles. Roman Manliness. Virtus and the Roman Republic. Nueva York: Cambridge UP, 2006.

Millar, Fergus. Rome, the Greek world and the East. The Roman Republic and the Augustean Revolution. Chapel Hill y Londres: The University of North Carolina Press, 2002. 
Nicolet, Claude. Roma y la conquista del mundo mediterráneo 264-27 a. C. Barcelona: Labor, 1984.

Nieto, Daniel. "Ciudadanía, política y diplomacia: una aproximación al fundamento civilizatorio y legitimador en la política exterior de Roma desde la Biblioteca Histórica de Diodoro de Sicilia”. Historias del Orbis Terrarum, n. ${ }^{\circ}$ 14, 2015, pp. 95-114

_. "Diplomacia y legitimación: Diodoro Sículo y la representación historiográfica del imperialismo romano”. Cuadernos de Historia Cultural, n. ${ }^{\circ}$ 2, 2013, pp. 28-60.

- Salustio y la identidad de Roma. Crisis politica y cambio cultural en el fin de la República. Córdoba: Editorial Brujas, Ordia Prima, Studia 11, 2021.

Pérez Frutos, Pedro. "Guerra y religión en la república romana: el ciclo militar de octubre”. Revista Universitaria de Historia Militar, vol. 5, n. ${ }^{\circ}$ 10, 2015, pp. 179-99.

Plutarco. Vidas paralelas, Bruto. Traducido por Marta González. Madrid: Gredos, 2009.

Rawson, Elizabeth. "La expansión de Roma”. Historia Oxford del Mundo Clásico. Roma, vol. 2. John Boardman y otros. Madrid: Alianza, 1988.

Rich, John. "Fear, Greed and Glory: the Causes of Roman War-Making in the Middle Republic". War and Society in the Roman World. Editado por J. Rich y G. Shipley. Londres y Nueva York: Routledge, 1993, pp. 38-68.

Sancho Royo, Antonio. "Introducción general". Apiano, Historia Romana, I. Madrid: Gredos, 1980.

Seaver, James E. "Publius Ventidius. Neglected Roman Military Hero". The Classical Journal, vol. 47, n. ${ }^{\circ}$, 1952, pp. 275-80.

Syme, Ronald. La revolución romana. Barcelona: Crítica, 2011.

Torregaray, Elena. "Viajar en representación de Roma: idas y venidas de los legatiembajadores". Viajes y cambios de residencia en el mundo romano. Editado por J. M. Iglesias Gil y A. Ruiz Gutiérrez. Santander: Publican, Ediciones Universidad de Cantabria, 2011, pp. 319-34

Veyne, Paul. "Humanistas: los romanos y los demás". El hombre romano. Editado por A. Giardina. Madrid: Alianza, 1991. 
Woolf, Gregory. "Roman Peace". War and Society in the Roman World. Editado por J. Rich y G. Shipley. Londres y Nueva York: Routledge, 1993, pp. 171-94

Ziolkowski, Adam. "Urbs Direpta, or how the Roman Sacked Cities". War and Society in the Roman World. Editado por J. Rich y G. Shipley. Londres y Nueva York: Routledge, 1993, pp. 69-91. 